\title{
Future City Glasgow: programas de ação, tensões e contradições em um projeto de smart city
}

Future City Glasgow: programs of action, tensions and contradictions of

\section{André Fabrício da Cunha Holanda}

Professor colaborador do Programa de Pós-Graduação em Comunicação e Cultura

Contemporâneas (PPGCCC) da Faculdade de Comunicação (FACOM) da Universidade

Federal da Bahia (UFBA) e pesquisador pós-doc (PDJ - CNPQ) do Lab 404 - Laboratório de

Pesquisa em Mídia Digital, Redes e Espaço do mesmo programa.

andreholanda73@gmail.com

\section{André Luiz Martins Lemos}

Professor titular do Departamento de Comunicação e do Programa de Pós-Graduação em Comunicação e Cultura Contemporâneas (PPGCCC) da Faculdade de Comunicação (FACOM) da Universidade Federal da Bahia (UFBA).

alemos@gmail.com

Recebido em 14 de outubro de 2015. Aprovado em 29 de março de 2016.

\section{Resumo}

$\mathrm{O}$ artigo aborda fatores econômicos ligados ao aparato de vigilância do espaço público no projeto Future City Glasgow, modelo para a adoção de padrões oficiais para projetos de smart cities no Reino Unido. Este estudo foi realizado no âmbito de uma rede internacional de pesquisadores em torno do projeto "Augmented urbanity and smart technologies: how 'smart' are our cities becoming?", financiado pelo Newton Fund. Utiliza-se a Teoria Ator-rede e um modelo brasileiro de classificação de projetos de smart cities, além da metodologia Infralab, da rede de pesquisas citada.

Palavras-chave: Smart city. Vigilância. Teoria Ator-rede. 


\section{Abstract}

This paper analyses economic factors related to the public space surveillance apparatus in the project Future City Glasgow, a model for official standards for smart cities in the United Kingdom. The study was carried out by an international network of researchers gathered around the project "Augmented urbanity and smart technologies: how 'smart' are our cities becoming?", funded by the Newton Fund. The article relies on the Actornetwork Theory, on a Brazilian model for the classification of smart cities projects, and on the Infralab methodology, under development by the aforementioned research network.

Keywords: Smart city. Surveillance. Actornetwork Theory.

\section{Introdução}

Em janeiro de 2014, o projeto Future City Glasgow (FCG) foi o vencedor de uma concorrência aberta pela Technology Strategy Board (TSB, atualmente Innovate UK) para a criação de um projeto-piloto para cidades, com uma verba de 24 milhões de libras esterlinas a ser gasta em 18 meses. A proposta do Conselho Municipal de Glasgow disputou essa verba com 29 cidades britânicas com o intuito de criar uma infraestrutura tecnológica capaz de utilizar as smart tecnologias ${ }^{1}$ no espaço urbano.

Como projeto-piloto de um programa oficial, o caso de Glasgow deve incidir diretamente sobre a definição de parâmetros para novas iniciativas, influenciando padrões técnicos oficiais como os Smart City Standards, em desenvolvimento pelo British Standards Institute (BSI) Daí seu interesse como primeiro caso a ser explorado pela rede internacional de pesquisa reunida em torno do projeto "Augmented urbanity and smart technologies: how 'smart' are our cities becoming?", financiado pelo Newton Fund (NEWTON Fund, 2016), reunindo pesquisadores do Brasil e do Reino Unido para a pesquisa comparativa de casos nos dois países, em busca da definição de parâmetros de avaliação para programas de smart city.

1 Podemos definir as smart tecnologias como dispositivos infocomunicacionais dotados de capacidade eletrônico-digital de processamento de informações para desempenhar diversas funções: captar informações em redes sem fio, transformá-las em dados digitais sobre o ambiente e processar grande quantidade deles, atuando de forma automática com pouca intervenção humana. No que se refere ao projeto em Glasgow, as ações preveem aprimoramento do controle de tráfego e policiamento, abertura de canais de acesso a dados abertos, aplicativos, entre outros. Para maiores detalhes, ver o site oficial do projeto em: $<\mathrm{http}$ ://futurecity.glasgow. gov.uk/>. 


\section{A metodologia Infralab}

Esta pesquisa exploratória desenvolve uma metodologia (a ser testada e aprimorada ao longo da cooperação) como modelo de investigação, e está baseada em entrevistas com atores-chave dos projetos estudados, bem como com usuários e opositores que possam trazer uma perspectiva crítica. Discussões coletivas são realizadas entre os pesquisadores, a fim de construir articulações do caso com as pesquisas individuais dos membros da rede de cooperação ${ }^{2}$. O pouco tempo disponível para trabalho de campo nesta fase exploratória requer que as interações com informantes e pesquisadores concentrem-se no aprofundamento das questões e debates. Os workshops duram três dias, sendo um de visitas, um de discussão sobre as experiências e um terceiro, de meio período, de sínteses e gestão da rede. É importante que a equipe proponente do caso não adiante as suas investigações, de modo a estar em pé de igualdade com o restante da rede. As entrevistas devem ser abertas e exploratórias, com um mínimo de preparação prévia para todos os envolvidos a partir de um briefing.

Realizam-se entrevistas com representantes selecionados entre proponentes, desenvolvedores, usuários e opositores, incluindo uma perspectiva crítica ao projeto. No intervalo entre as entrevistas, são realizadas, pelos membros da rede, discussões rápidas a fim de trocar impressões e debater pontos controversos ou que precisam ser aprofundados. Terminados os contatos com informantes, os pesquisadores devem refletir sobre os resultados preliminares até o workshop a ser realizado no dia seguinte, em que as interpretações e críticas são debatidas coletivamente. Ao final dos debates, todos saem com três questões a ser respondidas em um short paper com suas reflexões.

\section{Um modelo de smart cities}

Lemos e Mont'Alverne propõem o entendimento do conceito de smart city como a cidade "sensível ao ambiente", graças à intensa utilização e produção de dados pela ciência dos dados (Big Data) e pela Internet das Coisas. Os objetivos comuns a todo projeto de smart city seriam aumentar a eficiência da gestão urbana e da sua infraestrutura, melhorar a qualidade de vida e incentivar a atividade consciente dos habitantes pelas tecnologias digitais, promovendo a sustentabilidade, a economia criativa e o empoderamento

2 Fazem parte dessa rede de pesquisa o Programa de Pós-Graduação em Gestão Urbana da PUC-PR, o Programa de Pós-Graduação em Comunicação e Cultura Contemporâneas da UFBA, a School of Architecture, Design and Environment da Plymouth University e o Department of Geography da Durham University. 
dos cidadãos. Os autores recusam as proposições meramente instrumentais, voltadas para a dimensão utilitária de upgrade dos serviços e equipamentos já instalados.

Guiada por essas definições, a classificação dos projetos é feita segundo três eixos em primeiro lugar, quanto ao modelo conceitual, os autores identificam dois tipos básicos:

1. informacional/tecnológico, de cariz burocrático, calcado em paradigmas de vigilância e disciplina, no qual ganha destaque o papel dos aparatos técnicos de transmissão, registro e monitoramento da informação como fator de mudança;

2. sustentável/criativo, que não dispensa o uso de novas tecnologias, mas sua ênfase principal é outra. Trata-se de uma renovação do próprio caráter da cidade, guiada pela sustentabilidade e/ou economia criativa.

A interpretação que propomos é abordar essa classificação como uma escala ordenada segundo o potencial transformador dos projetos, partindo do menos (informacional/ tecnológico) para o mais transformador (sustentável/criativo).

Quanto ao segundo eixo de categorização, o tipo do projeto pode ser:

1. made from scratch, ou seja, criado sem uma base pré-existente;

2. centralizado, ou seja, criado e gerido por órgãos oficiais;

3. descentralizado, ou seja, criado por atores privados, com a colaboração da administração pública.

Finalmente, no eixo da "ação", cada projeto incide principalmente sobre três campos, de acordo com o foco prioritário de transformações propostas: infraestrutura, gestão urbana e open data.

Essa classificação marca aspectos dominantes, e não alternativas exclusivas. É de se esperar que a maioria dos projetos contemple simultaneamente os três campos (é o caso de Glasgow, como logo veremos), sendo que o modo como cada projeto os prioriza para investimento explicita um traço caraterístico da sua intenção.

Portanto, podemos propor um entendimento dos projetos como um conjunto de modelos: um modelo panóptico, calcado na infraestrutura de monitoramento e vigilância, no qual o cidadão é construído como mero objeto do escrutínio municipal; um modelo de gestão urbana, em que o cidadão se constitui como beneficiário de serviços públicos, com variável capacidade de crítica e colaboração; e um modelo de open data, mais aberto à participação e à transparência pública, no qual o Estado passa a ser construído como objeto do escrutínio por parte dos cidadãos. 
Cada modelo de smart city pode revelar uma contradição básica entre o projeto proposto à opinião pública, os órgãos de fomento e o sistema efetivamente implantado, contradição marcada pela tensão entre vigilância panóptica e transparência participativa. Segundo esse modelo, Glasgow seria uma experiência de tipo centralizada, na qual as ações principais são em open data (segundo os documentos apresentados) e em infraestrutura urbana (basicamente, monitoramento e vigilância). Ela foi concebida a partir de um edital, e a sua concepção de smart é tecnocrática. É preciso ter em mente que não há relação necessária entre projetos baseados em dados e propostas transformadoras, participativas ou de empoderamento. Cabe saber como se constrói o lugar das tecnologias da informação na cidade que se pretende smart, assim como cabe definir quais são o lugar e o papel do cidadão em cada regime estabelecido.

O nosso trabalho, aqui, será, portanto, examinar o FCG comparando as características do projeto proposto com as do sistema implantado, de modo a esclarecer suas prescrições para a relação fundamentalmente política entre cidadão e cidade ("inteligente").

\section{Um conto de duas cidades}

O modelo future city coloca forte ênfase em projetos de open data ${ }^{3}$. A leitura dos documentos e textos promocionais promete uma ampla abertura de dados governamentais já existentes, bem como a produção de novos, em sinergia com uma base social ativa e pulsante. No entanto, o que vimos foi um discurso hesitante entre liberdade e colaboração, tendo como ponto forte um grande aparato de monitoramento do espaço público: o Glasgow Operation Center (GOC). A impressão final é de que o projeto sugere uma preocupação "social" com as iniciativas de open data, mas elas parecem ser um apêndice em relação ao principal produto, que é o GOC.

Em Glasgow, o primeiro turno de trabalho de campo foi consumido com a visita aos escritórios do projeto e a entrevista com o diretor do programa, Gary Walker, seguida da visita ao GOC e de novas consultas com sua equipe, terminando com uma última reunião com a gestora do projeto, Amber Williams. Durante a tarde do mesmo dia, foram realizadas entrevistas de contraste com o assessor técnico, professor doutor Richard Bellingham, diretor do Institute for Future Cities da Universidade de Strathclyde, e com

3 Open data é a disponibilidade de datasets (conjunto de dados brutos) gerados pelos poderes públicos e/ou privados para uso público e gratuito. No Open Data Handbook, podemos ler esta simples definição: "Open data is data that can be freely used, re-used and redistributed by anyone - subject only, at most, to the requirement to attribute and sharealike." (WHAT...). Para mais informações, ver: <http://opendatahandbook.org/guide/ en/what-is-open-data/>. 
consultores independentes, afastados do projeto pelo conselho municipal para formar sua própria empresa, a Urban Tide.

O diretor Walker relatou os aspectos gerais do projeto perfeitamente de acordo com o que se pode considerar o discurso oficial. Open data e participação receberam atenção especial. Em seguida, foram apresentados os seus eixos principais: a integração de serviços de monitoramento e vigilância no Centro Integrado de Operações, a dimensão de open data e os programas demonstrators, que exemplificam as capacidades do projeto e as iniciativas para o engajamento da população.

O programa abrange uma ampla gama de serviços já prestados pelo conselho municipal, apresentados por meio de vídeos promocionais, e que o projeto deve tornar mais eficientes graças à participação dos usuários. Diversos serviços estão previstos para implantação ou reciclagem a partir das novas possibilidades informacionais - desde vigilância, segurança e gestão de crises, planejamento de rotas, coleta de lixo e iluminação pública inteligentes.

Walker destaca o grupo de demonstrators voltados a divulgar as capacidades do projeto, a fim de incentivar a participação popular e o desenvolvimento de novas soluções por iniciativa da própria sociedade. Tais programas abrangem os principais setores contemplados pelo projeto.

A eficiência energética se faz presente nos projetos de smart grid e intelligent street light. Além de se adequarem às condições de luz ambiente, os postes de iluminação serão ponto de acesso de wi-fi e trarão sensores de ruído, movimento e poluição. Já o aplicativo Glasgow Energy é voltado a monitorar o consumo doméstico em relação às médias municipais e informar o consumidor sobre como melhorar seu rendimento.

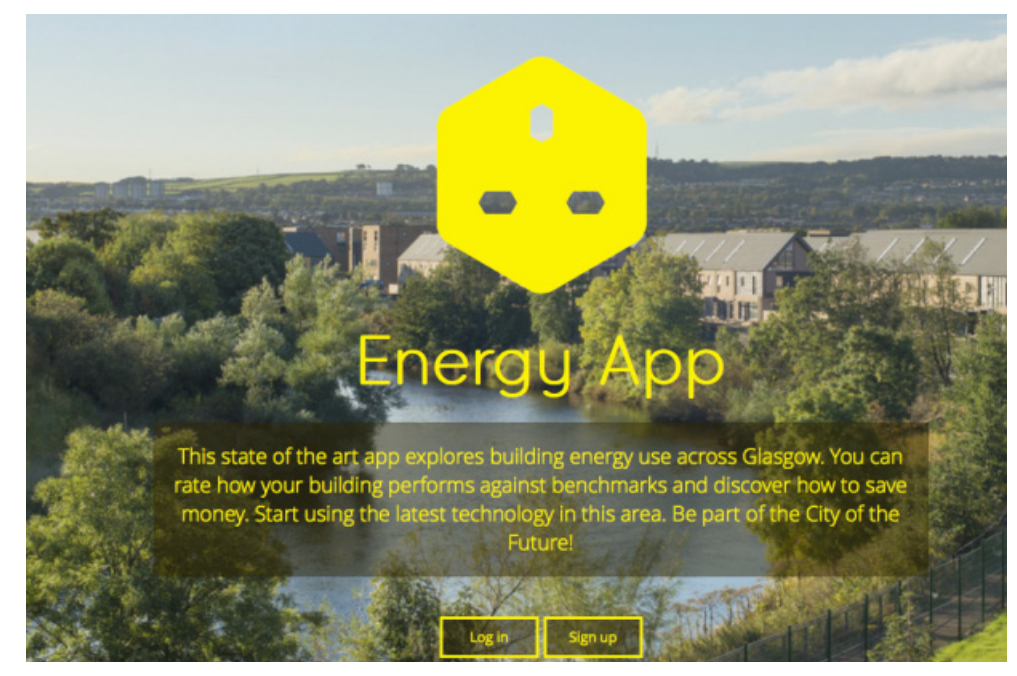

Figura 1. Tela inicial do aplicativo de gestão de energia do projeto 
O projeto Active Travel acompanha o fluxo da população e de turistas a pé ou de bicicleta, por meio dos aplicativos para dispositivos móveis Glasgow Walking e Glasgow Cycling. Ele também contempla o monitoramento contínuo do desempenho do transporte público atual, inclusive os serviços de "transporte social", destinados a pessoas com dificuldades de locomoção.

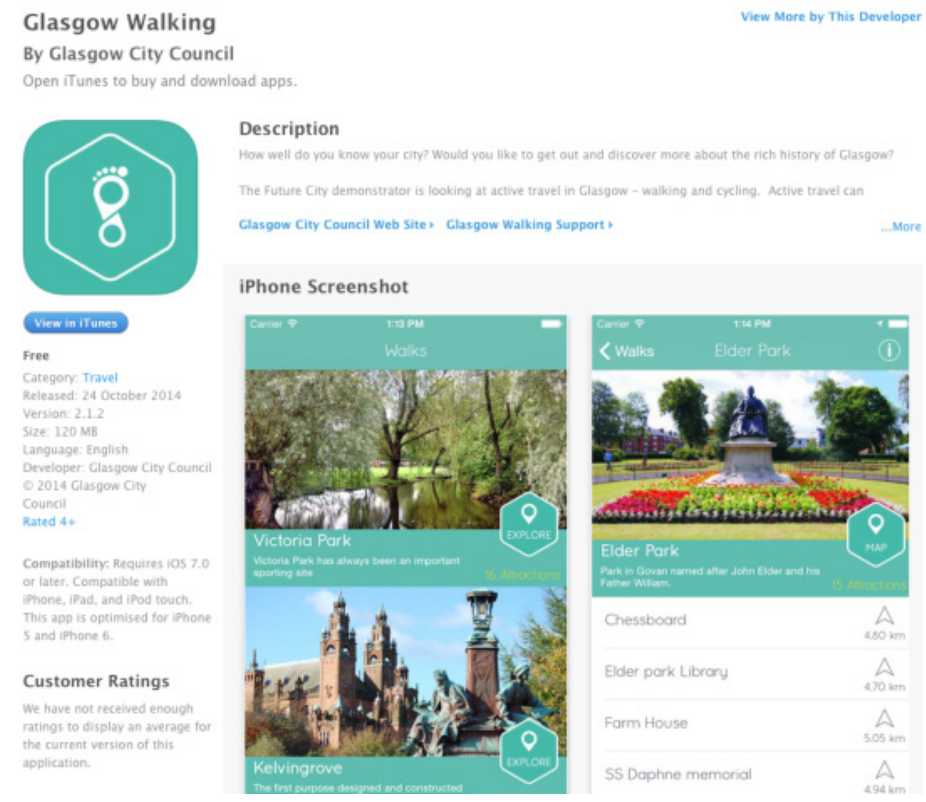

Figura 2. Aplicativo Glasgow Walking

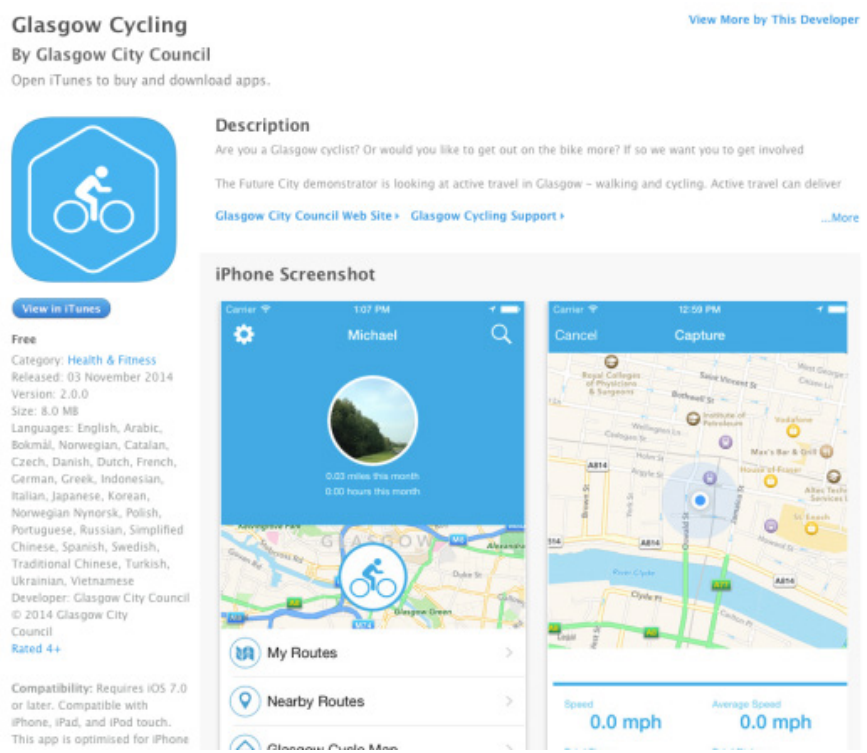

Figura 3. Aplicativo Glasgow Cycling 
O My Glasgow permite que o cidadão relate problemas, denuncie comportamentos impróprios e acompanhe reclamações anteriores. Essas queixas podem ir desde sujeira deixada por cachorros, lixo jogado de maneira inadequada ou não recolhido, parquímetros e semáforos quebrados, até denúncias de pichação. Os pedidos são geolocalizados e permitem a anexação de fotos.

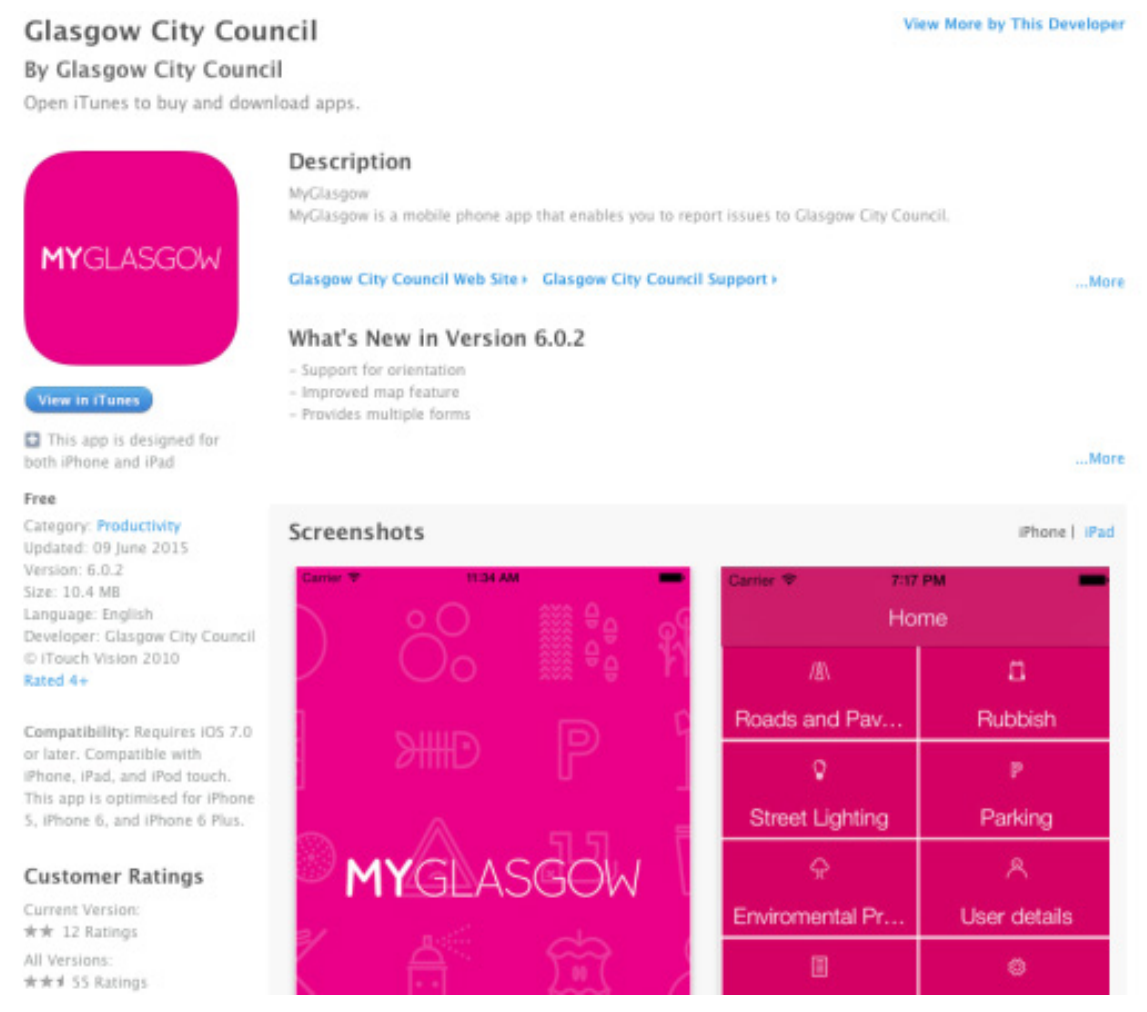

Figura 4. Aplicativo My Glasgow

A dimensão dos dados abertos, central no discurso promocional, está baseada no projeto Open Glasgow. Segundo Walker, essa iniciativa cumpre duas funções essenciais: a transparência da informação pública e o redesenho da oferta de serviços. Suas ações estão estruturadas em torno dos eixos planejamento, refinamento e otimização das políticas públicas, de um lado, e incentivo à inovação pela participação popular e de desenvolvedores e hackers, de outro. No entanto, trata-se de uma parceria com a Microsoft, articulação que parece indicar pouca afinidade do projeto com o movimento open data e seus parceiros habituais do software livre e hackers.

Os usuários do sistema, sejam pessoas físicas, associações ou organizações, são vistos como pertencentes a três categorias: provedores de informação, desenvolvedores e usuários finais. Surge aqui uma tensão quanto ao potencial de empoderamento do projeto: seu foco na participação ativa do usuário provoca uma nítida ruptura entre os que estão 
capacitados a desenvolver soluções e os que são simplesmente fontes de informação, papéis que cada vez mais se confundem na sociedade atual. O modelo de Glasgow joga com lógicas contraditórias, sendo, ao mesmo tempo, um projeto de controle e de open data. Essa dinâmica de presença e ausência aparece nas dimensões polarizadas da cidade "aberta e controlada".

Outra ruptura em relação ao discurso oficial é a revelação de tensões internas ao conselho quanto ao provimento das informações de cada setor e um dos grandes desafios do projeto, segundo seu diretor. Como aprendemos nas entrevistas, para além das questões de autonomia e política interna, parte do problema se deve à responsabilidade para com dados particulares dos cidadãos.

A relutância em entregar os dados de sua propriedade ou responsabilidade é resolvida na formulação do diretor Walker como uma troca (trade-off $f^{4}$ ) de dados em pagamento pela melhoria contínua dos processos e serviços. Trata-se do mesmo discurso que se confunde com o modelo de negócios de empresas como Google e Facebook. Vale ressaltar que esse é tipicamente o discurso legitimador da vigilância em prol da segurança.

Se isso foi um problema dentro da própria administração pública, a promoção do engajamento da população não poderia estar ausente do programa. Para divulgar o projeto, uma série de contêineres reciclados, equipados com painéis e tablets, são usados como engagement hubs, colocados nas ruas, com educadores que podem tirar dúvidas e informar a população sobre o projeto. Um Hackathon foi organizado para desenvolver aplicativos para quatro áreas temáticas - segurança, energia, saúde e transporte - durante quatro semanas. Com relação aos dados abertos, o FCG dedica grande atenção a práticas de mapeamento colaborativo, proporcionado pelo Community Mapping. A dimensão criativa da população mais jovem também se faz presente pelo Future Makers, voltado a ensinar programação de computadores para crianças (TANGENT GRAPHIC, 2014). A escolha dessa competência específica para "fazer o futuro" não deixa de ser sintomática.

Apesar de todo esse esforço, um aspecto peculiar do discurso oficial do projeto é a identificação do engajamento dos cidadãos com o papel de clientes dos serviços públicos e, concomitantemente, com o de fonte de dados (e soluções) destinados a aprimorar esses serviços. Observa-se, mais uma vez, a troca de dados por serviços de que, na verdade, o cidadão tem o direito de usufruir.

Some-se a isso a contradição já citada referente à associação entre o conselho e a Microsoft, que fornece todo o software para o projeto: toda a plataforma de hospedagem de dados, inclusive os servidores. O contrato aponta para uma relação contraditória do

4 Insistiremos na expressão inglesa trade-off, que capta melhor o caráter comercial dessa troca, com sua explícita noção de perda, ou seja, de abrir mão de uma coisa em favor de outra. 
conselho municipal com o modelo de open data, tema frequente nos discursos de legitimação, promoção e mobilização do projeto.

Para Kitchin (2014), o movimento open data caracteriza-se por considerar os dados não privativos como bens comuns (commons) que devem ser livres e gratuitos para todos os cidadãos. No entanto, para empresas como a Microsoft, os dados são mercadoria (commodity) protegida por propriedade intelectual. É notório o contraste com a sua atitude para com a captação e uso de dados dos usuários, feita sem nenhum tipo de controle, garantia ou compensação financeira para eles. Em que pese a flagrante contradição ideológica, a utilização de dados no caso Open Glasgow não é exclusividade estatal, já que eles ficam abertos tanto para os cidadãos (pelo Dashboard, sites, mapas e aplicativos), quanto para empresas e desenvolvedores.

Se queremos compreender as implicações políticas de todo o projeto e descobrir qual das duas cidades futuras será realmente implantada em Glasgow (a cidade participativa dos dados abertos ou a cidade tecnocrática do aparato de controle, monitoramento e vigilância instalado), precisamos explorar mais a fundo a rede de mediadores que a compõem.

\section{Panoramas e oligóptico}

Uma análise orientada pela Teoria Ator-rede (TAR) (LATOUR, 2012a) requer cautela quanto às conclusões da experiência. Seria preciso um trabalho maior de coleta dos "rastros" para montar completamente a rede e "ouvir" os diversos mediadores para entender a controvérsia sobre o que significa essa Glasgow futura e o adjetivo smart nessa smart city. Seria preciso identificar outros documentos fundadores, dar voz a outros atores (cidadãos de Glasgow, NGO), ouvir mais os responsáveis e analisar com profundidade o trabalho feito com os dados abertos; mas podemos, nesse momento, remontar a rede de mediadores percebida na experiência analisada aqui.

A visita ao Centro Integrado de Operações de Glasgow é liderada pela responsável e pelo diretor do projeto, com suas respectivas credenciais, que precisam ser usadas em portas automáticas para conceder acesso às instalações. As medidas de segurança adotadas não são maiores nem mais severas do que em qualquer organização típica. Existem, no entanto, indicações de que aquelas salas destinadas aos monitores, à gestão de crises, reuniões e escritórios comuns constituem um território próprio, aninhado no edifício do conselho municipal, com controle de identificação em pelo menos dois níveis de acesso. Em determinado momento, o próprio diretor geral não conseguiu abrir a sala dos monitores com suas credenciais e teve que esperar que a diretora do centro nos permitisse a passagem (não sem antes alertar que não seria possível fotografar o interior da sala, em 
respeito à privacidade dos cidadãos monitorados, ou seja, há um monopólio da intromissão concedido ao GOC).

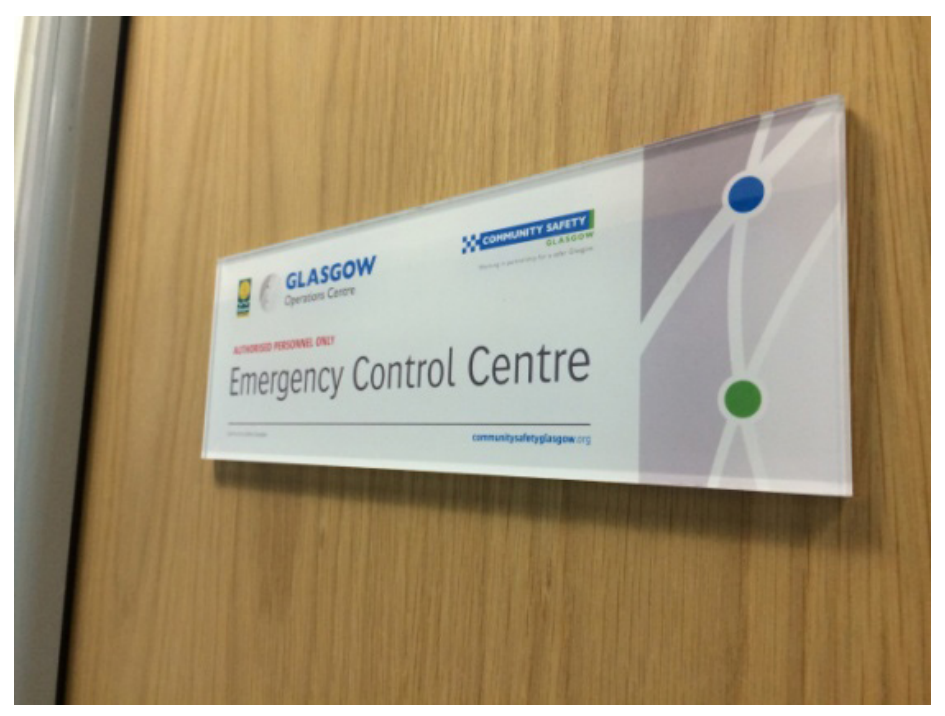

Figura 5. Única imagem permitida do Centro de Controle

Feita essa ressalva, a última porta se abre, e as ruas molhadas por um dia chuvoso tipicamente escocês se multiplicam nas 85 telas de 55 polegadas dispostas nas paredes à volta da sala, servindo, nessa primeira fase, a 500 das mais de 2.000 câmeras disponibilizadas pela Community Safety Glasgow (órgão municipal de segurança pública) e pelo Traffcom (responsável pelo fluxo de veículos), ambos funcionando de maneira integrada nas instalações. Os diretores informam que esse aparato de vigilância consumiu aproximadamente a metade dos recursos do projeto, principalmente pela infraestrutura do centro e pelo upgrade para o padrão HD das câmeras (lembremos: centenas na primeira fase, milhares no total).

Apesar de estar sob contínuo monitoramento por câmeras desde 1992, a população não recebeu bem o aumento da definição de imagem, manifestando novas preocupações quanto à privacidade e ao anonimato. Houve necessidade de nova negociação de limites e responsabilidades entre conselho municipal e cidadãos. Outro ponto que trouxe incômodos foi o software utilizado, que é capaz de identificar indivíduos, detectar invasões a espaços delimitados e até mesmo identificar comportamentos considerados suspeitos, como o abandono de pacotes ou de objetos, que poderia indicar um ataque terrorista, por exemplo.

A arquitetura da sala não é aquela típica do Centro de Operações do Rio de Janeiro (COR), em que os olhares de todos convergem para um mesmo painel, por sobre os 
monitores individuais nas bancadas ${ }^{5}$. No centro de Glasgow, não há nenhuma presença das redes sociais, demonstrando pouca atenção aos usos das formas sociais emergentes. À pergunta sobre a existência de "cientistas sociais" no projeto, a resposta foi negativa. A sua presença, lado a lado com engenheiros e programadores, poderia oferecer elementos importantes para pensar a "inteligência real e prática" da cidade à qual o projeto se dirige.

No centro escocês, os painéis são setorizados por função: tráfego e segurança ficam permanentemente focados nos seus próprios painéis. Em cada parede, os diferentes setores ficam lado a lado, de costas para os setores do lado oposto da sala. No meio do espaço, bancadas e armários de arquivos espaçados para dar passagem entre os lados sugerem uma divisão ao comprido da sala.

Um fato que chamou a atenção dos pesquisadores foi a presença de grandes mapas de papel sobre essas bancadas. Segundo um dos funcionários, a finalidade é permitir a reunião dos colaboradores em torno de um objeto em comum, com capacidades comunicativas e interativas tradicionais que os sofisticados equipamentos e software disponíveis na sala, assim como a sua própria arquitetura, parecem dificultar.

Um exemplo interessante de composição entre modalidades diversas de dispositivos de monitoramento é a articulação permanente entre as câmeras e os mapas (digitalizados ou não) que as localizam no espaço urbano. A principal função dos operadores humanos, nesse caso, é compor um panorama do espaço urbano fragmentado nas telas em um mosaico de imagens desconexas, a princípio indecifráveis como representação seja do espaço, seja da vida urbana. É pela articulação entre câmeras e mapas, por meio dos painéis, redes de computadores, operadores humanos, regulamentos e protocolos, compondo uma rede atuante que não registra de fato a realidade urbana, mas a sintetiza continuamente, que é possível instaurar uma imagem global da cidade nessa sala. Esse "local conector e estruturador” (LATOUR, 2012a, p. 261) constrói a conexão entre local e global, entre o espaço da interação e seu contexto, pela articulação entre mediadores (humanos e não humanos) que registram (em alta definição) pequenos fragmentos da cidade real.

Embora estejamos em um centro de vigilância, a rede montada nos mostra que não estamos em frente a nenhum tipo de panóptico, mas a um panorama composto por oligópticos articulados em rede. Como afirma Latour,

5 O centro está muito aquém da experiência do COR, que, além do monitoramento tradicional por câmeras, permite a visualização do comportamento de outras dimensões da cidade (problemas de iluminação, radar meteorológico, trabalhos de infraestrutura sendo realizados nas vias urbanas, situação dos semáforos etc.) e se dirige a problemas concretos (violência, trânsito caótico, falta de energia elétrica, deslizamento de terras por causas de chuvas, entre outros). O COR congrega as principais instituições públicas no mesmo espaço, além de manter um canal aberto com a sociedade. 
os oligópticos são lugares assim porque fazem exatamente o oposto dos panópticos: veem muito pouco para alimentar a megalomania do inspetor ou a paranoia do inspecionado, mas o que veem, veem bem [...] Graças aos oligópticos, vistas pujantes, mas muito estreitas do todo (conectado) se tornam possíveis - enquanto as conexões subsistem (LATOUR, 2012a, p. 262, grifos nossos).

A relação entre cada oligóptico (a rede montada no Centro de Operações) e o panorama (da cidade) não representa uma diferença de escalas na vida social. Essa modulação entre escalas é feita pelos próprios atores, pela articulação entre meios de registro e representação ã câmera e mapa, por exemplo. A construção do conhecimento, aqui, se dá pelo encadeamento de referências entre o mapa, as telas, os sistemas informatizados, os humanos e o espaço urbano visualizado. Aqui, “a escala é a própria realização do ator" (LATOUR, 2012a, p. 267), a composição da "big picture 6 "، que dá sentido aos eventos, como a imagem de um contexto mais amplo que enquadra os fragmentos captados pelo monitoramento municipal.

De fato, a Grande Imagem é apenas isso: uma imagem. [...] Contrariamente à oligóptica, os panoramas, como a etimologia sugere, veem tudo. Mas podem também não ver nada, já que simplesmente mostram uma imagem pintada (ou projetada) na minúscula parede de uma sala totalmente fechada para o exterior (LATOUR, 2012a, 270-271).

A sala do Centro de Controle de Glasgow é um ambiente fechado, e sua atuação como articulador de localização panorâmica do urbano é evidente. Já em sentido inverso, ele não oferece transparência para que os cidadãos tenham acesso a essa visão panorâmica. Esse é o panorama que nos interessa aqui (LATOUR, 2012a, 265 et seq.). Questionados nesse sentido, os diretores defenderam o fechamento do seu “território informacional" (LEMOS, 2011) em nome da privacidade do cidadão. Toda territorialização é constituída em torno da necessidade de controlar fluxos e de criar hierarquias de privilégios de acesso aos recursos de uma rede específica. No presente caso, o cidadão (em razão de quem tudo isso foi construído) é, mais uma vez, considerado cliente do serviço, que impõe limites ao seu funcionamento, mas, ao mesmo tempo, é o objeto de monitoramento.

6 Referência à expressão anglófona "the big picture", equivalente ao nosso "contexto mais amplo" ao qual é sempre necessário enquadrar nossas discussões. Ex.: "É preciso analisar a questão com referência a um contexto mais amplo". 
Essa mistura aparentemente contraditória que caracteriza o cidadão como objeto de controle e, simultaneamente, como sua fonte legitimadora, não é novidade nas ciências sociais e políticas. Esse monopólio de controle a que aludimos antes é perfeitamente análogo ao monopólio da violência concedido ao Leviatã de Hobbes pelos homens livres a fim de evitar a guerra de todos contra todos (CALLON; LATOUR, 1981).

Vimos pelo menos dois exemplos dessas traduções autorizadoras do poder: 1) a assimetria de visibilidade do Centro Integrado de Operações de Gasgow, legitimado pela sua diretora como defesa da privacidade do cidadão; 2) o discurso dos vídeos promocionais em que os dados pessoais e os rastros dos deslocamentos e ações do cidadão são o recurso principal para construir o futuro da cidade, criando uma deliberada tensão entre a propriedade sobre os dados e a responsabilidade.

Precisamos avaliar como os fatores econômicos têm distanciado o projeto do foco em ações de open data a fim de caracterizá-lo em uma escala polarizada entre modelos mais centralizados versus mais participativos de smart cities.

A entrevista com Amber Williams, gestora do projeto, confirma que aproximadamente a metade dos recursos (12 milhões de libras esterlinas) foi gasta com a construção do Centro Integrado de Operações. Na avaliação dela, essa destinação foi programática e caracteriza um equilíbrio entre o lado de vigilância e o Open Glasgow. Outra interferência de fatores econômicos no andamento do projeto foi o spin-off' que gerou a empresa Urban Tide, criada por três ex-consultores do FCG que viram a oportunidade de levar o projeto a outras cidades. A iniciativa gerou desconforto junto ao conselho municipal, que acabou desligando-os.

Há a winda outra ruptura conectada de maneira menos óbvia a fatores econômicos. Durante entrevista realizada com o professor Richard Bellingham, diretor do Institute for Future Cities da University of Strathclyde e representante da comunidade acadêmica na elaboração do projeto, ele parece sentir-se alienado com relação ao desenvolvimento do projeto por não ver atendida sua visão específica do que seja uma smart city e de qual seja, nesse contexto, a função dos dados mobilizados. Para ele, o desenvolvimento do projeto foi pressionado por fatores como o curto prazo para a aplicação das verbas (18 meses), que o professor caracteriza como "uma janela de oportunidade que não poderia ser desperdiçada". É fácil perceber como essa pressa impediu um melhor desenvolvimento da proposta, em especial justificando a destinação da metade da verba à atualização do aparato tecnológico já instalado.

7 O termo spin-off designa o projeto que é desdobramento de um produto anterior, derivado daquele, mas autônomo para todos os efeitos. Por exemplo, uma consultoria formada por funcionários após o sucesso de um projeto em que tenham atuado junto. 


\section{Mapeando as traduções do projeto}

Tendo realizado essa breve descrição das associações que compõem a rede que exploramos, inclusive apontando algumas contradições nos discursos e articulações organizacionais que nos podem ajudar a desestabilizar as caixas-pretas aí alocadas, podemos mapear os mediadores principais do projeto, bem como as divergências surgidas entre os seus programas de ação.

Infelizmente, não é produtivo representar no mapa toda a complexidade dos pontos mais densos da rede. Separamos a composição do projeto da sua implantação, diferenciando, dessa forma, dois sentidos do projeto: o documental, que conquistou as verbas, e o ator-rede efetivamente implantado, que a vem transformando em uma rede de dispositivos técnicos, contratos, arranjos sociais e organizacionais.

$\mathrm{Na}$ figura a seguir, o aspecto inacabado em todo o setor superior à direita é representado por linhas menos nítidas, em alusão à sua condição de projeção. Outra simplificação requerida foi a eliminação dos itens como aplicativos, sites e programas de ação específicos, uma vez que boa parte deles só existe como promessa.

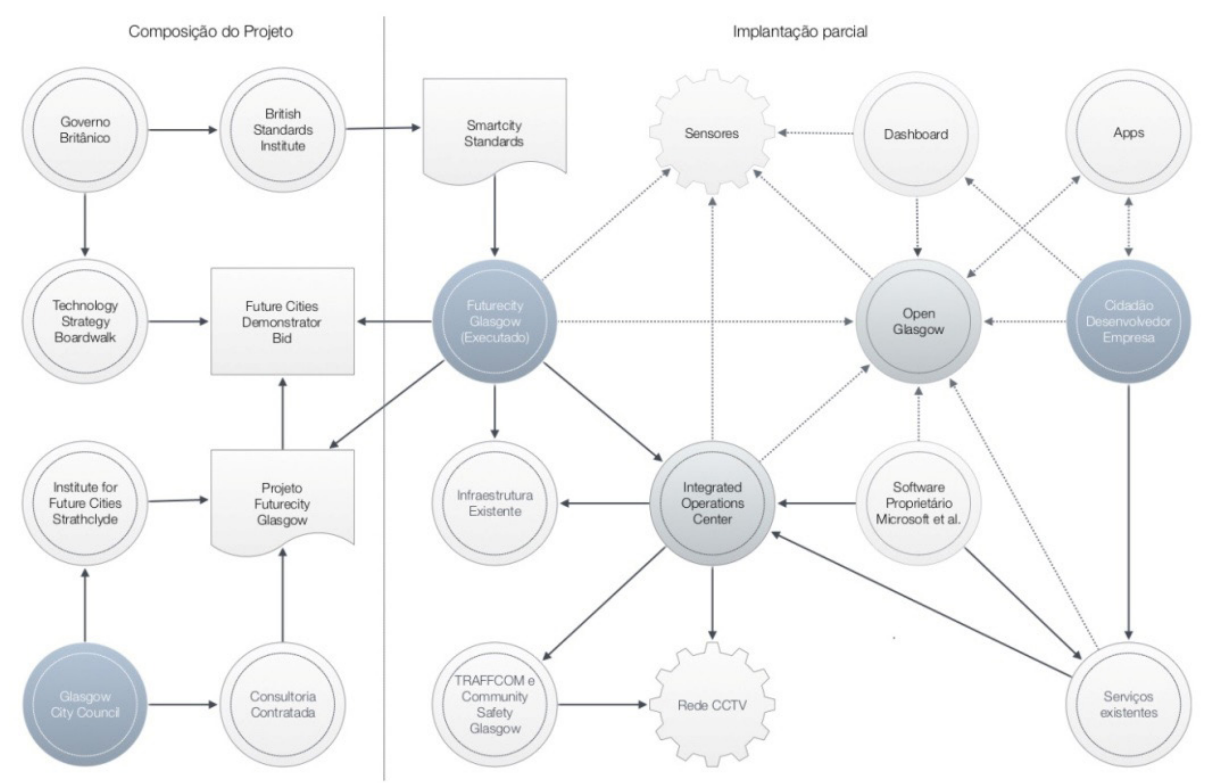

Figura 6. Mapa dos principais mediadores do Future City Glasgow

Fonte: Elaboraração própria

Após todas essas escolhas construtivas, o mapa mostra três circuitos bastante diferenciados. À esquerda do mediador Futurecity Glasgow (Executado) fica o projeto que conquistou as verbas governamentais, enquanto, à sua direita, percebem-se claramente 
dois hubs em graus de implantação diferenciados, representados pelas setas pontihadas: o Integrated Operations Center, que recebeu prioridade consumindo a metade das verbas, e o Open Glasgow, que permanece em construção, ao qual escolhemos incorporar todos os aspectos do software interativo baseado em dados que ele pretende mobilizar e cujas conexões estavam longe da conclusão durante a pesquisa.

A princípio, não há nada de errado com essa priorização, mas esses três circuitos sugerem que o projeto (documento) funciona como uma mediação retórica para a conquista das verbas aplicadas no segundo (executado). A concentração concorrente entre os hubs de vigilância e o Open Glasgow não está claramente representada no discurso oficial do projeto. Ele, como já vimos, traduz como empoderamento o fornecimento de dados que pode ser considerado como método de controle e, no limite, de vigilância distribuída, negociado nos termos do trade-off tradicional entre segurança e controle. Houve claramente um desvio nas prescrições do projeto, no sentido de favorecer a dimensão de controle e vigilância.

Para explorar as contradições entre os atores responsáveis por essas prescrições do projeto, vamos partir da escala proposta por Lemos e Mont'Alverne, com base na qual podemos propor uma projeção dos focos discordantes dos três atores fundamentais da definição do projeto FCG e sugerir uma leitura particular desse processo de ruptura.

Temos, no gráfico a seguir, entre chaves, em primeiro lugar, a Urban Tide, representante principal da proposta contida no Open Manifesto, que, apesar de centralizador, está parcialmente identificado com os valores do movimento open data. $\mathrm{O}$ outro elemento representa a posição do professor Billigham, cuja perspectiva é pragmática e tradicional e não vê sentido em abrir dados desestruturados para usos imprevistos, princípio essencial do movimento open data. Seu ideal é a publicação de dados específicos e utilitários que possam servir de subsídio para a atuação de cidadãos e servidores públicos, em direção ao aprimoramento de sistemas e da sustentabilidade. 


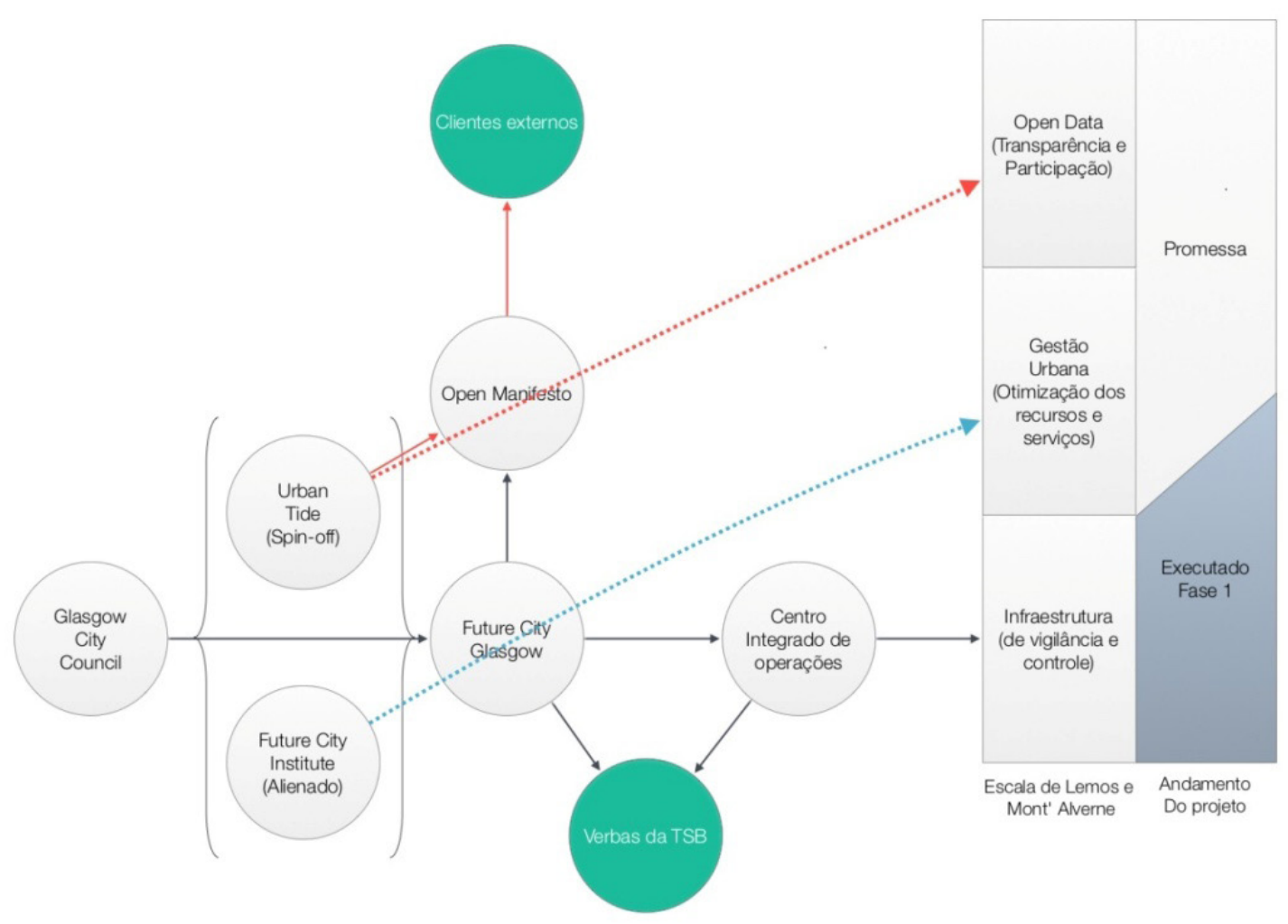

Figura 7. Trajetórias dos mediadores do projeto inicial após ruptura Fonte: Elaboração dos autores

Essa figura tenta mostrar que, entre essas duas vozes, existem desacordos fundamentais de foco (linhas pontilhadas) que podem explicar os respectivos movimentos após a ruptura com o projeto. Os mediadores em verde são econômicos, fontes de capital, e nos permitem compreender as forças que lançaram a Urban Tide (trajetória contínua na cor vermelha) para fora da órbita do Conselho Municipal de Glasgow, assim como as razões pelas quais esse último (bem como o projeto como um todo) parecem estar presos ao nível da infraestrutura de vigilância e monitoramento da "Present" City Glasgow. Resultados parciais. É difícil ignorar as diversas contradições entre a perspectiva de abertura e transparência do movimento open data e as razões econômicas de empresas e administração pública.

As prescrições legadas pelo parque tecnológico instalado, marcadamente identificado com modelos tradicionais de monitoramento e vigilância do espaço público, com altos custos de manutenção e atualização, articuladas às prescrições que acompanham a concessão de financiamento público (inclusive a especificação de um tempo máximo de 18 meses para aplicação) levaram o projeto a ser fortemente baseado na atualização da tecnologia instalada, sem desmerecer o aspecto de integração das funções competentemente 
realizada, limitando bastante (pela metade) o potencial dessas verbas para fomentar novas formas de cidadania.

Podemos agora retomar o termo smart cities. Ele é interessante, pois nos permite justamente ressaltar a controvérsia. Devemos perguntar: como este adjetivo, smart, pode gerar mais conhecimento sobre uma política do espaço? Em que lugar parecem estar colocados os cidadãos? Qual é, afinal, a cidadania prescrita por esse modelo? Quão smart se torna o cidadão de Glasgow?

Não se pode dizer que tenhamos encontrado um mero objeto de uma tecnopolítica de vigilância específica, tampouco encontramos o cidadão empoderado por uma nova era de transparência e de participação. Como mostra a Tabela 1, a perspectiva do conselho resume a cidadania à relação de trade-off entre os seguintes direitos em troca de deveres.

Tabela 1. Trade-off característico da smart citzenship projetada pelo projeto FCG

\begin{tabular}{|c|c|}
\hline Direitos & Deveres \\
\hline Utilizar os serviços e estruturas municipais; & $\begin{array}{l}\text { Fornecer os dados destinados a aprimorar a eficiência } \\
\text { desses serviços e estruturas; }\end{array}$ \\
\hline trafegar por rotas eficientes e seguras; & $\begin{array}{l}\text { fornecer seus dados de deslocamento para auxiliar a } \\
\text { gestão desse fluxo; }\end{array}$ \\
\hline $\begin{array}{l}\text { habitar uma comunidade ou ocupar temporariamente } \\
\text { espaços públicos vigiados e controlados para a } \\
\text { manutenção da segurança. }\end{array}$ & $\begin{array}{c}\text { colaborar com a vigilância distribuída por meio de } \\
\text { aplicativos e sites. }\end{array}$ \\
\hline
\end{tabular}

Fonte: Elaboração dos autores

O traço fundamental desse projeto tem sido o engajamento do cidadão em termos estritamente limitados ao trade-off entre benefício em troca de dados, típico dos modelos de negócios característicos da economia informacional. Situa-se, portanto, no polo diametralmente oposto ao movimento open data sugerido pelo discurso oficial. Mesmo com a eventual implantação dos projetos Open Glasgow e seus subprodutos (Data Launch Pad, Dashboard e demais aplicativos), não há razão para crer que o papel fundamental do cidadão deixe de ser o de se constituir como um provedor de dados para o aprimoramento da alocação e funcionamento de serviços e recursos.

Trata-se de um modelo, de acordo com a proposta de Lemos e Mont'Alverne, tecnocrático, centralizado, de infraestrutura, notadamente voltado para vigilância e controle. O projeto pode ser classificado como informacional-tecnológico, apesar das propostas específicas de sustentabilidade e da promessa de incentivo à economia criativa. Quanto ao tipo, a iniciativa é claramente centralizada, e, quanto à ação (apesar do discurso em torno do conceito de open data), tem sido, até o momento, francamente focada na 
infraestrutura, com promessas de atingir as características do padrão de gestão urbana, a partir da implantação das fases interativas.

O resultado mais significativo dessa primeira aproximação é a constatação da distância entre projeto, resultados parciais e resultados previstos, que pode ser facilmente explicada pelos aspectos econômicos da execução. Espera-se que esteja perfeitamente claro que não se adota aqui uma perspectiva de denúncia de interesses ocultos que manipulam e distorcem os objetivos iniciais do projeto. Nosso interesse recai sobre os desvios do programa de ação causados pela problemática e difícil composição desse peculiar ator-rede a partir de mediadores tão díspares como câmeras HD, Microsoft, aplicativos, dados, consultores independentes e servidores públicos, que interferem continuamente nos percursos uns dos outros, à medida que convergem ou são arremessados para fora da órbita dessa composição específica.

\section{Referências}

OPEN Glasgow. Future City Glasgow: a day in the life. 25 set. 2014. Disponível em: <https:// www.youtube.com/watch?v=5n0wX3_QLrc >. Acesso em: 20 maio 2015.

BRITISH STANDARDS INSTITUTION. The role of standards in smart cities: issue 2. Ago. 2014. Disponível em: <http://www.bsigroup.com/LocalFiles/en-GB/smart-cities/resources/The-Role-of-Standards-in-Smart-Cities-Issue-2-August-2014.pdf >. Acesso em: 5 maio 2016.

CALLON, M; LATOUR, B. Unscrewing the big Leviathan: or how actors macro-structure reality and how sociologists help them to do so. In: KNORR-CETINA, K.; CICOUREL, A. V. Advances in social theory and methodology: toward an integration of micro-and macro-sociologies. London: Routledge, 1981. p. 277-303.

COUNCIL Leader opens Glasgow's new hi-tech operation centre. Disponível em: $<$ https://www. glasgow.gov.uk/index.aspx?articleid=11217>. Acesso em: 4 out. 2014.

DEUZE, M. Media life. [S. 1.]: Polity, 2012.

TANGENT GRAPHICS. Future City Glasgow: what is a future city? 24 abr. 2014. Disponível em: <https://www.youtube.com/watch?v=lDWNqcPeZ74>. Acesso em: 20 maio 2015.

FUTURE Makers Introduction. Open Glasgow, 16 out. 2014. Disponível em: <http://open.glasgow. gov.uk/futuremakers/>. Acesso em: 06 maio 2016.

GOW, G. A. Privacy and ubiquitous network societies. In: ITU WORKSHOP ON UBIQUITOUS NETWORK SOCIETIES. Proceedings... Geneva: 2005.

KITCHIN, Rob. The data revolution: big data, open data, data infrastructures and their consequences. London: Sage, 2014. 
LATOUR, B. Reagregando o social: uma introdução à teoria do Ator-rede. Salvador: Edufba; Bauru: Edusc, 2012a.

.Enquête sur les modes d'existence: une anthropologie des modernes. Paris: La Découverte, $2012 b$.

LEMOS, A. Locative media and surveillance at the boundaries of informational territories. In: FIRMINO, R. J.; DUARTE, F.; ULTRAMARI, F. ICTs for mobile and ubiquitous urban infrastructures: surveillance, locative media and global networks. New York: IGI Global, 2011. p. 129-149.

NEWTON Fund. British Council, 2016. Disponível em: <http://www.britishcouncil.org/education/science/ newton>. Acesso em: 2 maio 2016.

WHAT is open data? Open Data Handbook. Disponível em: $<$ http://opendatahandbook.org/guide/ en/what-is-open-data/>. Acesso em: 5 maio 2016.

$20 \frac{\text { Comunicação \& Inovação, PPGCOM/USCS }}{\text { v. 17, n. 34 (1-20) maio-ago. } 2016}$ 